\title{
The effects of magnetic water treatment for improving germination of some
}

\author{
medicinal plants \\ تأثثر المياه المعالجة مغناطيسياً في تحسين إنبات بعض النباتات الطبية \\ Khalid A. Rasheed Sattar A. Shlahi \\ Hayder H. Ismail Mohammed Umar A. M. Ahmad \\ Biotechnology Research Center/ Al-Nahrain University \\ خالد عباس رشيد ستار عبالله شلاهي حيار حقي إسماعيل محم عمر عبداللطيف \\ مركز بحوث التقنيات الاحيائية / جامعة النهرين \\ E-mail: k_rasheed@yahoo.com
}

\begin{abstract}
Three magnetic fields $(2000,3000$ and 4000$)$ guass were used to study the germination of five types of medicinal plant seed (Nigella sativa, Coriandrum sativum, Cuminum cyminum, Eruca sativa and Foenicutum. vulgare). The seeds were incubated in the dark and in certain moisture at three different temperature levels $(10,18 \text { and } 22)^{\circ} \mathrm{C}$ for 14 days. During the growth experiments, the best temperature of germination was found at $18^{\circ} \mathrm{C}$, where it excelled three seed of five and gave a high percentage of germination to $F$. vulgare $E$. sativa $C$. sativum. Magnetic fields showed a differential effect in plant seed with different temperature. Where the seeds of $F$. vulgare and $C$. sativum gave the highest percentage of germination at $18^{\circ} \mathrm{C}$.
\end{abstract}

Keywords: magnetic water treatment, germination, medicinal plants.

ستخذمت ثلاثة مجالات مغناطيسية (2000 ، 3000 و 4000) غاوس لدراسة إنبات خمسة أنواع من بذور النباتات الطبية المتمثلة

الملخص

بـ (Nigella sativa, Coriandrum sativum, Cuminum cyminum, Eruca sativa and Foenicutum. vulgare). تم

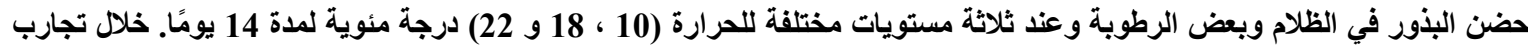

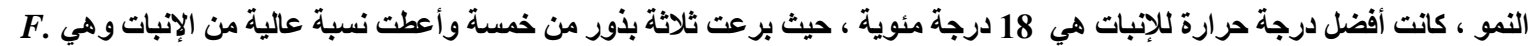

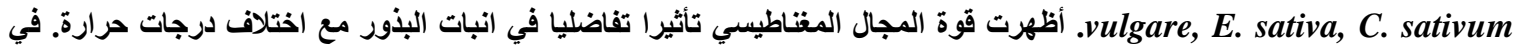
حين أعطت بذور نباتي C. sativum و F. vulgare أعلى نسبة من الإنبات عند 18 درجة مئوية.

الكلمات الدالة : المياه المعالجة مغناطيسيا ، الاتبات ، النباتات الطبية.

\section{Introduction}

Magnetic technology has been used in many applied fields in many countries of the world, including some Arab countries such as Egypt, Sudan, United Arab Emirates, Saudi Arabia and Syria [1]. Magnetic water treatment is carried out using magnetic devices called Magnetron, as the water is passed through it with a certain intensity and for a specified period [2]. Studies have shown that the treatment of water magnetically change many of its physical and chemical properties including surface tension and viscosity, increase polarity of water and reduce the number of water molecules that are droplets by dismantling the hydrogen bonds that bind these molecules together, and these changes that get to the water after treatment magnetically make it lighter and easier to absorb by which contributes to accelerating the plant's vital processes and positively affect its growth and development [3]. The degree of water treatment magnetically depends on three factors [4], volume of fluid passing through the magnet, magnetism required to expose the liquid and the fluid contact time with magnet (duration of treatment). Water is classified as a magnetic material that consists of complete orbits. If it is exposed to a magnetic field, it interferes with these spheres and the water molecules are perpendicular to the magnetic flux lines [4]. 
These materials can not retain the magnetic effect for a long time after removing the magnetic field, where they may be losing after 12 - 48 hours depending on the three factors mentioned above [5].

Water is one of the most important factors in the success of plant growth. Researchers have recently used magnetic technology in all agricultural fields, including irrigation water magnetically because of its positive effects in plant growth and flowers. Magnetic technology adapts the properties of water and makes it more capable of dissolving and washing the salt from the soil as well as absorbing nutrients from the soil solution [2]. The loss of seed for their vitality has made it imperative to raise the efficiency of germination, especially herbal plants in order to increase the proportion and speed of germination, and the surface layer of the soil, especially in calcareous may prevent those seeds from germination. This can be addressed by magnetic technique, where seed and water are magnetized for such purpose [6].

\section{Materials and methods}

Five locally available plants were used (Nigella sativa, Coriandrum sativum, Cuminum cyminum, Eruca sativa and Foenicutum. vulgare) to finding the effect of magnetic water treatment on the percentages of germination at three different temperature and the adoption of these degrees of temperature for laboratory germination and field agriculture. This is based on what was mentioned by [8].

Three magnetic fields were utilized to show the difference between the magnets represented by 2000 , 3000 and 4000 gauss. Depending on that mentioned by the US GMX company. The magnetic systems were built with a half-inch diameter. In order to demonstrate the effect of the magnetic field on the water, the retention time of the liquid was calculated during the magnetic system and exposure time. Fifteen minutes the time required to calculate the retention time that a certain volume of water need to pass through the required magnetic intensity. While the water is kept after passing through magnetic field for 10 minutes to starting laboratory experiments, for the purpose of raising the potential of water through the coordination of its bonds and raising the energy of the water interaction with the seed components [9].

Measurement of some physical properties of water before and after magnetization with a different magnetic field to find out the effect of different magnetic fields on water for laboratory experiments such as $\mathrm{pH}, \mathrm{EC}(\mu \mathrm{S} / \mathrm{cm})$, viscosity $(\mathrm{y})$ and surface tension $(\overline{\mathrm{Y}})$.

The seeds of the five plants were cultured in cooling incubator at three different temperature levels depending on the plant selected in the experiments. The experiments lasted for 14 days for each plant, indicating differences in magnetized water before and after the experiment to show the failure and growth of each plant in the experiment.

\section{Results and discussion}

Table (1) shows a clear difference in water measurements before and after the use of magnetic intensity for the studied specifications. The table shows the changes in water parameter by magnetic field of 4000 gauss, where the highest changes in the studied specifications were observed. The percentage of change was $45.2 \%$ for electrical conductivity, then surface tension with $17.91 \%$, followed by viscosity $16.17 \%$, while the $\mathrm{pH}$ was only slightly increased by $9.21 \%$. This results were agreed with $[9,10]$. These changes are important in the seed germination process, especially for the value of $\mathrm{pH}$, although the percentage of change is minor but lead to the transformation of the acidic environment to the simple basal (slightly basic), where the seed grows through which plants grow better than it is the acid environment [11]. Viscosity and surface tension also has an active role in germination and therefore, has a greater function in field culturing [12]. The electrical conductivity as low as 4000 gauss has the greatest effect in reducing the concentration of salts by dissolving it in water due to the polarization caused by the magnetic effect of the water molecule [13]. 
Table (1): Some values of physical variables before and after magnetization. with percentages of variation.

\begin{tabular}{|c|c|c|c|c|}
\hline Parameters & Control & $2000 \mathrm{G}$ & $3000 \mathrm{G}$ & $4000 \mathrm{G}$ \\
\hline pH & 7.1 & 7.4 & 7.4 & 7.82 \\
\hline$\%$ & & 5.37 & 5.37 & 9.21 \\
\hline $\mathrm{EC}(\boldsymbol{\mu S} / \mathrm{cm})$ & 250 & 175 & 170 & 137 \\
\hline$\%$ & & 30 & 32 & 45.2 \\
\hline Viscosity (y) & 0.068 & 0,061 & 0.06 & 0.57 \\
\hline$\%$ & & 10.3 & 11.76 & 16.17 \\
\hline Surface tension $(\overline{\mathbf{Y}})$ & 0.067 & 0.057 & 0.055 & 0.055 \\
\hline$\%$ & & 14.92 & 17.91 & 17.91 \\
\hline
\end{tabular}

Seed performance can be improved before planting with some physical methods such as exposing to the electric field, magnetic or microwave are effective for improving without damage to the environment through the affecting the physiological and chemical processes in the seeds, thus contributing to the highest vitality and strength of the seeds [14]. The seeds which processed magnetically grow rapidly, due to stimulate the formation of protein necessary for the growth of the root and lead to the activation of metabolic processes in vulnerable seeds [14], and the moisture of seeds which magnetically treated before cultivation was less than $14 \%$.

In laboratory germination experiments, the seeds were incubated in a dark incubator with a certain relative humidity for the purpose of sustaining the experiment and maintaining the vitality of the seeds. The experiments showed that some seeds were sprouting faster than the other seeds. Table 2 shows that Foenicutum vulgare seeds outperformed the other seed plants in terms of germination at this temperature $\left(10^{\circ} \mathrm{C}\right)$ with germination rates ranging from $100-150 \%$ compared with control plant seeds, followed by Cuminum cyminum seeds which increased by $14.28 \%$ than the control. While the other three seeds of plants did not show any obvious effect of the magnetic intensity and vice versa, there was a negative impact at the 2000 and 3000 Gauss (Tables 2). From these experiments, can be concluded that low temperatures have a negative effect on their germination [15].

Table (2): Percentage of germination of five seeds incubated at $10{ }^{\circ} \mathrm{C}$

\begin{tabular}{cccccc}
\hline Plant seeds & F. vulgare & E. sativa & C. sativum & N. sativa & C. cyminum \\
\hline Control & 20 & 60 & 80 & 60 & 70 \\
2000G & 50 & 30 & 35 & 40 & 60 \\
3000G & 40 & 50 & 60 & 70 & 80 \\
4000G & 50 & 60 & 60 & 50 & $\mathbf{8 0}$ \\
\hline
\end{tabular}

When the temperature was raised to $18{ }^{\circ} \mathrm{C}$, the seeds of these plants showed clear differences. All plant seeds were superior to those of control plants except for Cuminum cyminum, which failed to produce positive results due to the increased of magnetic intensity. But with 2000 guass, its excess of $11.76 \%$, thus increasing can be taken in the field culture with this intensity only, this result has already been mentioned by Reina et al. [16]. The highest value of the effect of bio-magnetism was recorded in $C$. sativum seeds, was $114.28 \%$ and the lowest were recorded from $N$. sativa seeds, which reached $7.14 \%$. In both degrees of temperature, the seeds of N..sativa did not show any significant effect of increasing magnetism (Table 3).

Table (3): Percentage of germination of five seeds incubated at $18{ }^{\circ} \mathrm{C}$

\begin{tabular}{cccccc}
\hline Plant seeds & F. vulgare & E. sativa & C. sativum & N. sativa & C.cyminum \\
\hline Control & 40 & 70 & 35 & 70 & 85 \\
2000G & 45 & 75 & 25 & 70 & 95 \\
3000G & 45 & 60 & 55 & 75 & 80 \\
4000G & 60 & 90 & 75 & 75 & 75 \\
\hline
\end{tabular}


When the temperature was raised to $22{ }^{\circ} \mathrm{C}$, it was noticed that these seed plants recorded many differences in the process of germination, where three seeds of plants failed to give a positive result ( Eruca sativa, Coriandrum sativum and Cuminum cyminum), while there was a significant difference in germination of seeds Nigella sativa.This value is considered as low compared with the seeds of the plant Foenicutum. vulgare, which recorded the highest value of germination reached up to $25.58 \%$, and it also cannot be considered a significant impact of the bio-magnetic field in the production process, but can be adopted in laboratory experiments (Table 4).

Table (4): Percentage of germination of five seeds incubated at $22{ }^{\circ} \mathrm{C}$

\begin{tabular}{|c|c|c|c|c|c|}
\hline Plant seeds & F. vulgare & E. sativa & C. sativum & N. sativa & C. cyminum \\
\hline Control & 77 & 60 & 83.3 & 73.3 & 44.8 \\
\hline 2000G & 90 & 83.3 & 70 & 70 & 70 \\
\hline 3000G & 80 & 73.3 & 90 & 70 & 46.6 \\
\hline 4000G & 96.7 & 56.7 & 56.7 & 83.3 & 40 \\
\hline
\end{tabular}

Table (4) also shows that the seeds of Nigella sativa and Coriandrum sativum were failing to give a positive result with the magnetism used in comparison to the control plants. Whereas, Foenicutum vulgare recorded different response to magnetic expansion. The seeds of Eruca sativa showed a variable differences in germination and not clear at $10{ }^{\circ} \mathrm{C}$ and $22^{\circ} \mathrm{C}$. While, the seeds of Cuminum cyminum showed a positive germination results at $22^{\circ} \mathrm{C}$. There may be some effects that interfere with germination rates, most importantly the age of the seeds used and the temperature imbalance in the incubator because of the fluctuation in the electrical current or its interruption at night, in addition to the imbalance of moisture in the incubator [17].

Therefore, the thermal degree of $18^{\circ} \mathrm{C}$ can be considered the best in terms of germination of most experimental seeds and is the basis for agriculture in the field, with consideration the suitable magnetic field for each seed plant for the purpose of increasing production in terms of growth and bio-efficiency [18]. It has been proven through experience plants that have a great speeding in the growth of embryonic roots during the process of transition from the stage of self-reliance on their food stock to the stage of carbon representation, have a higher productivity and a more developed and developed a radical system [19].

Acknowledgment: I would like to thank the Research and Development Directory/Ministry of Higher Education and Scientific Research for its support in this study.

\section{References}

1. Mahjoub, Yasser Abbas (2004): Principles and Prospects of Magnetic Therapy. Journal of Health and Medicine, UAE. 31: 12-15

2. Takatchenko, Y. P. (1997). Hydromagnetic aero-ionizers in the system of Spray, Method of irrigation of agricultural crops. Hydromagnetic Systems and their role in creating Micro- climate. Chapter From Prof. Tkatchenko's book, Practical Magnetic technology in Agriculture, Dubai, 1997.

3. Kronenberg, K. J. (1985). Experimental evidence for effects of magnetic fields on moving water.IEEE Transactions on Magnetic, 21: 2059-2061.

4. Kronenberg, K. J. (2011). Magneto hydrodynamics: The effect of magnets on fluids. GMX International. http://gmxinternational.com/facts/magneto.htm

5. Al-Najim, F.Abdul Latif, Zakia Q. Mohammed and Diaa A. Tuwaij. (2004). Physics. Ministry of Education. Iraq.

6. Hillal, M. H.; and M.M. Hillal. (2000a). Application of magnetic technology in desert agriculture. I. Seed germination and seedling emergence of some crops in a saline calcareous soil. Egypt J. Soil Sci. 40 (3): 413-422.

7. Hillal, M.H.; and M.M. Hillal. (2000b). Application of magnetic technology in desert agriculture. II- Effect of magnetic treatments of irrigation water in salt distribution in olive and citrus field and induced changes of ionic balance in soil and plant. Egypt. J. Soil Sci. 40(3): 423-435.

8. Al-Attiyat, Ahmed (1979). Medicinal and aromatic plants in the Arab world, the university institution for studies and publishing.

9. Baran, B., Oksana B. and Vosyl G. (2006). Water system after magnetic field. Environmental Research, Engineering and Management. 4(38):19-23.

10. Ageel K., Hazem M. Rasheed and Ali S. Fares (2013). The effect of magnetic treatment of water in the prevention of deposits of carbonate calcium. Baghdad Journal of Science. 10 (1): 74-83. 
11. Hasaani, A. S. , Hadi, Z. and Rsheed K. A. (2015). Experimental study of the interaction of magnetic fields with flowing water. International J. of Basic and Applied Science. 3(3): 1-8.

12. Al-Tabakchali, A. M. (2012). Effect of growth regulators (CPPU) and Bressinolide and magnetic field strength in the growth and flowering of two varieties of Antirrhinum majus plant. PhD thesis, Faculty of Agriculture / University of Baghdad.

13. Yassin, B. Taha (1992). Water tension physiology in the plant. Directorate of the Library. University of Mosul / Iraq.

14. Ichiro, O. and S. Ozeki (2005). Dose magnetic treatment of water changes its properties. J. Phys. Chem. 110 (4): 1509-1512.

15. Fairgrieve, J.D. (2011). Magnetic Treatment of Seeds. Life Streams International Mfg. Co. 5203 Moore Road, Westmoreland, NY 13490 USA. http://www.wholly-water.com/magnetizer/plant.htm

16. Mohammed, E. Sultan (1983). Vegetable seeds production. Directorate of the Library. University of Al Mosul. Iraq.

17. Reina, F., L. Pascual and I. Fundora (2001). Influence of a stationary magnetic field of water relations in lettuce seeds. Part II. Experimental results. Bioelectromagnetic, 22(8): 595-602.

18. Shukri, I. F. Hassan (2002). Response of the plant, Coriandrum sativum L. to date of nitrogen fertilization and their effect on growth and production of pilot oil. Master degree - Department of Horticulture / Faculty of Agriculture - University of Baghdad, Iraq

19. Al-Maathidi, A. F. (2006). Effect of magnetic technology on some Ornamental plants. Ph. D. Thesis, College of Agriculture, University of Baghdad. 